Original Article

\title{
Weight control behaviors among Koreans
}

\author{
KIM SANG DoL ${ }^{1)}$ \\ 1) Department of Nursing, College of Health Science, Kangwon National University: 346 Hwangjo-gil, \\ Dogye-eup, Samcheok-si, Gangwon-do 245-907, Republic of Korea
}

\begin{abstract}
Purpose] This study was performed to investigate the weight control behaviors among Koreans. [Subjects and Methods] The study is a secondary analysis. Data were extracted from the Korea National Health and Nutrition Examination Survey from 2010 through 2014. [Results] The weight control behaviors were exhibited by more than half of the participants each year. The weight control behavior that was most prevalent among Koreans was exercise. The types of exercise included walking, muscle strengthening, flexibility exercises, etc. [Conclusion] These findings indicate that exercise was confirmed as the preferred method for weight control among Koreans. Key words: Weight control, Walking exercise
\end{abstract}

(This article was submitted Dec. 30, 2016, and was accepted Feb. 20, 2017)

\section{INTRODUCTION}

In general, weight control helps maintain an ideal body weight. Ideal body weight does not include the following conditions: overweight, obese, or underweight. The prevalence of overweight and obesity has been increasing globally ${ }^{1-4)}$. Overweight and obesity contributes to global health risks and critical issues. These conditions have been identified as a causal factor in a variety of physical or psychological problems such as diabetes, hypertension, cardiovascular disease, metabolic syndrome, anxiety, depression, disability adjusted life, life lost, etc ${ }^{1-5}$. In 2010 , the death rate due to overweight and obesity was estimated at approximately 3.4 million people globally ${ }^{4}$. Furthermore, obesity has evocated to social or economic problems as it has led to the following issues: poor academic performances, inability to work, low quality of life, social maladaptation, and a threat mortality globally ${ }^{5}$. As stated, in spite of major global risks, previous research findings suggested that there were little evidence of successful intervention strategies to aide in prevention of the overweight and obesity conditions ${ }^{4}$. Accordingly, measures of the weight control are required to reduce risks caused by overweight and obesity as well as prevent these conditions.

Weight control programs are known primarily as physical activity and diet therapy. Of these benefits of regular physical activity on physical well-being included promoting cardiorespiratory fitness, physical functioning maintaining healthy weight, and reducing risks for metabolic diseases etc ${ }^{6-8)}$. This infers that physical activity can be an important tool in preventing obesity. In order for physical activity to be effective in weight control, a qualified exercise therapist or physiotherapist should be instructed. First of all, it is necessary for people to examine their weight control methods. Then it is needed to confirm that people are using their weight control methods appropriately. Therefore, the purpose of this study was to investigate weight control behaviors among Koreans.

\section{SUBJECTS AND METHODS}

This study is a secondary analysis study, which used data extracted from the Korea National Health and Nutrition Examination Survey (KHNES) from 2010 through 20149). The total number of participants was 40,485 Koreans. All participants were over 9 years of age, with the exception of 618 people who were under the age of 6 and therefore non-applicable. The 
Table 1. General characteristics on participants

\begin{tabular}{lccccc}
\hline \multicolumn{1}{c}{ Variables /Year } & 2010 & 2011 & 2012 & 2013 & 2014 \\
\hline Gender & & & & & \\
Male & $4,115(45.9)$ & $3,867(45.4)$ & $3,634(45.1)$ & $3,634(45.1)$ & $4,115(45.9)$ \\
Female & $4,843(54.1)$ & $4,651(54.6)$ & $4,424(54.9)$ & $4,424(54.9)$ & $4,843(54.1)$ \\
Total & $8,958(100)$ & $8,518(100.0)$ & $8,058(100.0)$ & $8,018(100.0)$ & $7,550(100.0)$ \\
Age & & & & & \\
$1-9$ & $1,142(12.7)$ & $1,010(11.9)$ & $865(10.7)$ & $946(11.8)$ & $856(11.3)$ \\
$10-18$ & $1,076(12.0)$ & $942(11.1)$ & $900(11.2)$ & $959(12.0)$ & $718(9.5)$ \\
$19-29$ & $846(9.4)$ & $755(8.9)$ & $706(8.8)$ & $804(10.0)$ & $690(9.1)$ \\
$30-39$ & $1,342(15.0)$ & $1,204(14.1)$ & $1,085(13.5)$ & $1,097(13.7)$ & $1,032(13.7)$ \\
$40-49$ & $1,279(14.3)$ & $1,163(13.7)$ & $1,067(13.2)$ & $1,200(15.0)$ & $1,035(13.7)$ \\
$50-59$ & $1,245(13.9)$ & $1,265(14.9)$ & $1,187(14.7)$ & $1,142(14.2)$ & $1,134(15.0)$ \\
$60-69$ & $1,081(12.1)$ & $1,090(12.8)$ & $1,090(13.5)$ & $942(11.7)$ & $1,010(13.4)$ \\
$70<$ & $947(10.6)$ & $1,089(12.8)$ & $1,158(14.4)$ & $928(11.6)$ & $1,075(14.2)$ \\
Total & $8,958(100)$ & $8,518(100.0)$ & $8,058(100.0)$ & $8,018(100.0)$ & $7,550(100.0)$ \\
Weight control & & & & & \\
Yes & $3,129(34.9)$ & $2,933(34.4)$ & $2,602(32.3)$ & $2,338(29.2)$ & $2,307(30.6)$ \\
No & $604(6.7)$ & $538(6.3)$ & $447(5.3)$ & $485(6.0)$ & $462(6.1)$ \\
Non-applicable (<6 years) & $19(0.2)$ & $41(0.5)$ & $139(1.7)$ & $186(2.3)$ & $232(8.7)$ \\
No answer & $570(6.4)$ & $623(7.3)$ & $721(8.9)$ & $741(9.2)$ & $659(8.7)$ \\
System missing values & $4,636(51.8)$ & $4,383(51.8)$ & $4,149(51.5)$ & $4,268(53.2)$ & $3,890(51.5)$ \\
Total & $8,958(100)$ & $8,518(100.0)$ & $8,058(100.0)$ & $8,018(100.0)$ & $7,550(100.0)$ \\
\hline
\end{tabular}

sampling framework of the KHNES used population and housing census data available at the time of the most recent sample design. Through KHNES, data could be extracted to create a representative sample of target people, over the age of one, who live in the Republic of Korea. The Korea National Health and Nutrition Examination Survey consisted of a health survey, nutrition survey, and health screening. The health survey was investigated by interview and self-recorded methods. Weight control refers to whether or not there was effort to control weight in the previous 12 months. Weight control behaviors means that the participant is to mark all methods used to reduce or maintain their weight during the past year. Walking exercise means that participates walked daily for a minimum of over 10 minutes at a time during the previous week. Strengthening exercise means that participants performed push-ups, dumbbell, barbell, or horizontal bar during the previous 7 days. Flexibility exercises meant that participants performed stretching or barre gymnastics during the previous week. Statistical analyses were conducted using the SPSS program (version 18.0) for Windows. All data are presented as numbers (percentages).

\section{RESULTS}

Variables are presented in Table 1 and Figs. 1 and 2. The weight control was performed more than half of the participants at each year. The weight control behavior that was most prevalent among Koreans was exercise. The types of exercise included walking, muscle strengthening, flexibility exercises, etc.

\section{DISCUSSION}

The study results indicate that the weight control behaviors were exhibited by more than half of the participants each year. The weight control behavior that was most prevalent among Koreans was exercise. The types of exercise included walking, muscle strengthening, flexibility exercises, etc. These findings indicate that exercise was confirmed as the preferred method for weight control among Koreans. According to the 2002 National Health Interview Survey approximately $36 \%$ of adults, over the age of 18 , had used complementary and alternative medicine for weight control in the United State ${ }^{6)}$. Among the complementary and alternative medicine for weight control in the United States, $57.4 \%$ had used a yoga ${ }^{6)}$. Previous research findings suggested that yoga plays an important role in ideal body weight maintenance, prevention of obesity, and risk reduction for diseases due to overweight and obesity ${ }^{5}$. Additionally, previous research suggested regular physical exercise or activities have multiple benefits, such as standard physical functioning, maintaining healthy weight, and mental well-being ${ }^{8)}$. Prior research indicates that a lifestyle modification model is required to prevent overweight and obesity ${ }^{8)}$. Prior research indicated that measuring the process of change, using the transtheoretical model, of physical activity and exercise 

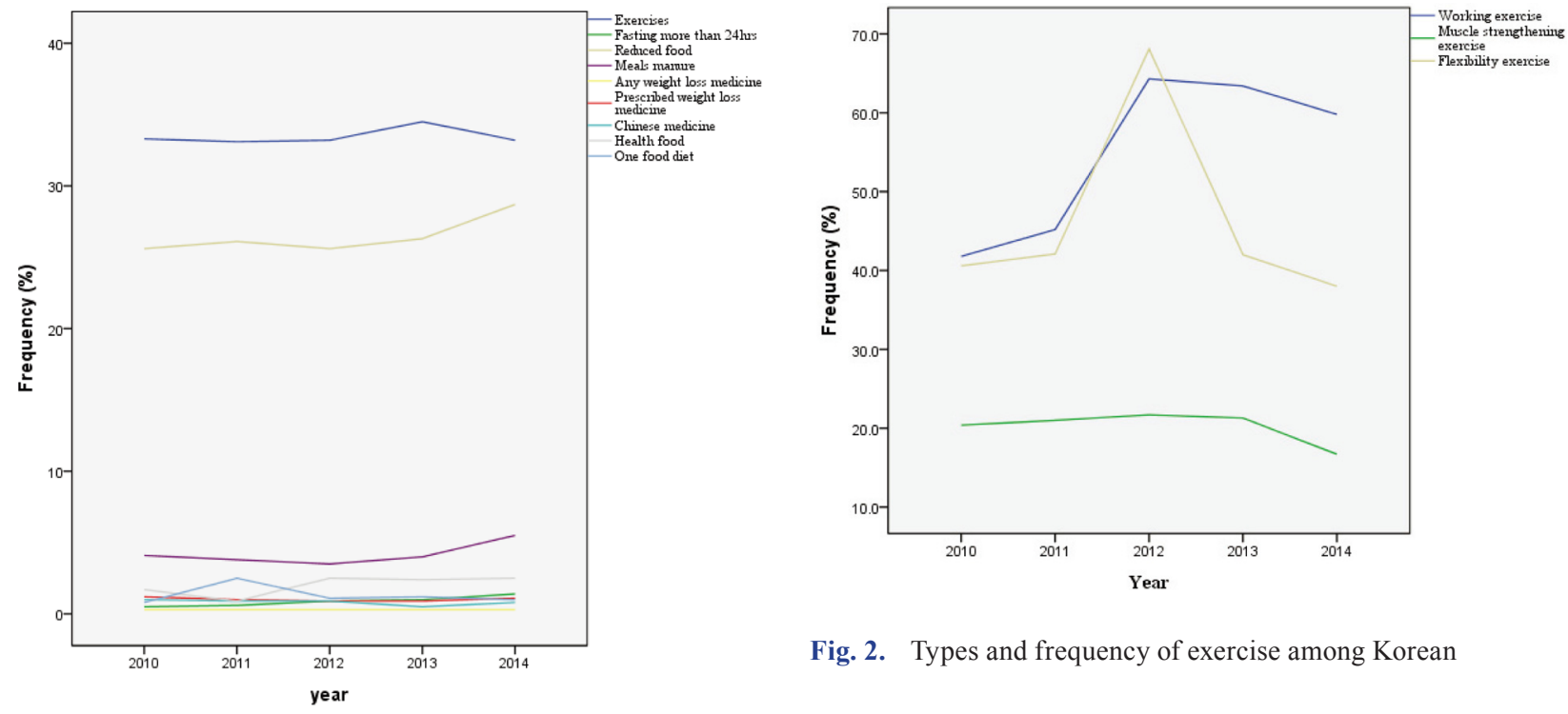

Fig. 2. Types and frequency of exercise among Korean

Fig. 1. Weight control behaviors among Korean

in overweight and obese adults supports the validity of the factorial structure for weight management ${ }^{10)}$. Contrary to positive research findings, one study found that a progressive resistance exercise program with high-speed components was not effective in improving the physical function of older women with sarcopenic obesity ${ }^{11)}$. The multicomponent intervention including behavioral self-monitoring, computer-based training, and motivational interviewing for truck drivers was supported in the United States ${ }^{12}$. Additionally, diet or eating behavior programs were recommended for management of overweight and obesity ${ }^{13-15)}$. Findings suggest obesity management and prevention efforts require multifaceted strategies incorporating education, health policy, public health and health systems, strong primary care workforce, etc ${ }^{16}$ ). The findings suggest that, among Korean, walking exercise programs should be offered to obese and implemented as a continuous program ${ }^{17)}$. Research found that aerobic exercise reduces weight and improves cardiopulmonary fitness in obese subjects more effectively than anaerobic exercise ${ }^{18)}$. A mentored obesity management program including mentoring, physical exercise, and nutrition education was effective in lowering BMI and increasing self-esteem of childhood obesity ${ }^{19}$.

In the future, creative new approaches must be developed to promote awareness of specific eating behaviors, decrease responsiveness to high-calorie foods, reduce stress-related eating, increase motivation to adhere to weight loss strategies, engage individual's social networks and communities to encourage physical activity, improve sleep patterns, and change habitual dietary behaviors ${ }^{9}$. However, in spite of various ways to manage obesity, Koreans seem to prefer exercises.

In conclusion, walking, muscle strengthening, and flexibility exercises are the primary strategies for weight control among Koreans according to survey data from 2010 to 2014. However, follow up on the effects of exercises for weight control among Koreans is needed.

\section{REFERENCES}

1) Chang T, Ravi N, Plegue MA, et al.: Inadequate hydration, BMI, and obesity among US adults: NHANES 2009-2012. Ann Fam Med, 2016, 14: 320-324. [Medline] [CrossRef]

2) Diniz MF, Beleigoli AM, Ribeiro AL, et al.: Factors associated with metabolically healthy status in obesity, overweight, and normal weight at baseline of ELSA-Brasil. Medicine (Baltimore), 2016, 95: e4010. [Medline] [CrossRef]

3) Flegal KM, Kruszon-Moran D, Carroll MD, et al.: Trends in obesity among adults in the United States, 2005 to 2014. JAMA, 2016, 315: 2284-2291. [Medline] [CrossRef]

4) Ng M, Fleming T, Robinson M, et al.: Global, regional, and national prevalence of overweight and obesity in children and adults during 1980-2013: a systematic analysis for the Global Burden of Disease Study 2013. Lancet, 2014, 384: 766-781. [Medline] [CrossRef]

5) Rioux JG, Ritenbaugh C: Narrative review of yoga intervention clinical trials including weight-related outcomes. Altern Ther Health Med, 2013 , 19 : 32-46. [Medline]

6) Sharpe PA, Blanck HM, Williams JE, et al.: Use of complementary and alternative medicine for weight control in the United States. J Altern Complement Med, 2007, 13: 217-222. [Medline] [CrossRef]

7) Zhao G, Li C, Ford ES, et al.: Leisure-time aerobic physical activity, muscle-strengthening activity and mortality risks among US adults: the NHANES linked mortality study. Br J Sports Med, 2014, 48: 244-249. [Medline] [CrossRef]

8) Belle SH, Stevens J, Cella D, et al.: Overview of the obesity intervention taxonomy and pooled analysis working group. Transl Behav Med, 2016, 6: 244-259. [Medline] [CrossRef] 
9) Korea National Health and Nutrition Examination Survey. https://knhanes.cdc.go.kr/knhanes/ (Accessed Nov. 11, 2016)

10) Romain AJ, Bernard P, Hokayem M, et al.: Measuring the processes of change from the transtheoretical model for physical activity and exercise in overweight and obese adults. Am J Health Promot, 2016, 30: 272-278. [Medline] [CrossRef]

11) Vasconcelos KS, Dias JM, Araújo MC, et al.: Effects of a progressive resistance exercise program with high-speed component on the physical function of older women with sarcopenic obesity: a randomized controlled trial. Braz J Phys Ther, 2016, 20: 432-440. [Medline] [CrossRef]

12) Olson R, Wipfli B, Thompson SV, et al.: Weight control intervention for truck drivers: the SHIFT Randomized Controlled Trial, United States. Am J Public Health, 2016, 106: 1698-1706. [Medline] [CrossRef]

13) Omidvar S, Amiri FN, Bakouei F, et al.: Weight-related concerns and diet behaviors among urban young females: a cross-sectional study. J Family Med Prim Care, 2016, 5: 326-330. [Medline] [CrossRef]

14) Leong SL, Gray A, Haszard J, et al.: Weight-control methods, 3-year weight change, and eating behaviors: a prospective nationwide study of middle-aged New Zealand women. J Acad Nutr Diet, 2016, 116: 1276-1284. [Medline] [CrossRef]

15) Garcia-Alvarez A, Mila-Villarroel R, Ribas-Barba L, et al. PlantLIBRA PFS Consumer Survey Group: Usage of Plant Food Supplements (PFS) for weight control in six European countries: results from the PlantLIBRA PFS Consumer Survey 2011-2012. BMC Complement Altern Med, 2016, 16: 254. [Medline] [CrossRef]

16) Denise CS, Sharma AM: Improving obesity prevention and management in primary care in Canada. Curr Obes Rep, 2016.

17) Son S, Jeon B, Kim H: Effects of a walking exercise program for obese individuals with intellectual disability staying in a residential care facility. J Phys Ther Sci, 2016, 28: 788-793. [Medline] [CrossRef]

18) Al Saif A, Alsenany S: Aerobic and anaerobic exercise training in obese adults. J Phys Ther Sci, 2015, 27: 1697-1700. [Medline] [CrossRef]

19) Lee GY, Choi YJ: Effects of an obesity management mentoring program for Korean children. Appl Nurs Res, 2016, 31: 160-164. [Medline] [CrossRef] 